Provided by the author(s) and University of Galway in accordance with publisher policies. Please cite the published version when available.

\begin{tabular}{|c|c|}
\hline Title & $\begin{array}{l}\text { Care relationships, quality of care and migrant workers caring } \\
\text { for older people. Ageing \& Society }\end{array}$ \\
\hline Author(s) & Walsh, Kieran \\
\hline $\begin{array}{l}\text { Publication } \\
\text { Date }\end{array}$ & 2013 \\
\hline $\begin{array}{l}\text { Publication } \\
\text { Information }\end{array}$ & $\begin{array}{l}\text { Walsh, K., Shutes, I. (2013) 'Care relationships, quality of care } \\
\text { and migrant workers caring for older people. Ageing \& } \\
\text { Society'. Ageing And Society, } 33 \text { (3). }\end{array}$ \\
\hline Publisher & Cambridge Journals Online \\
\hline $\begin{array}{l}\text { Link to } \\
\text { publisher's } \\
\text { version }\end{array}$ & http://dx.doi.org/10.1017/S0144686X11001309 \\
\hline Item record & http://hdl.handle.net/10379/3818 \\
\hline DOI & http://dx.doi.org/DOI: 10.1017/S0144686X11001309 \\
\hline
\end{tabular}

Downloaded 2023-04-26T10:02:49Z

Some rights reserved. For more information, please see the item record link above. 


\title{
Care relationships, quality of care and migrant workers caring for older people
}

\author{
KIERAN WALSH* and ISABEL SHUTES $\dagger$
}

\begin{abstract}
Migrant care workers make a substantial contribution to older adult care in Ireland and the United Kingdom (UK). However, little is known about the relational aspects of care involving migrant care workers and older people. Given that the care relationship is closely linked to quality of care, and that the Irish and UK sectors are increasingly restricted by economic austerity measures, this lack of information is a concern for care practice and policy. Our paper explores the relationship between migrant care workers and older people in Ireland and the UK and draws on data collected in both countries, including focus groups with older people $\left(\mathrm{N}=4_{1}^{1}\right)$, interviews with migrant care workers $(\mathrm{N}=9 \mathrm{O})$ and data from a survey of and interviews with employers. The findings illustrate the complexity of the migrant care workerolder person relationship; the prevalence of need orientated, friendship and familial-like, reciprocal, and discriminatory interlinking themes; and the role of individual, structural and temporal factors in shaping these relationships.
\end{abstract}

KEY WORDS - older people, migrant care workers, care relationship, quality of care.

\section{Introduction}

The care relationship between migrant care workers (registered nurses and care assistants) and older people is not well understood in Ireland and the United Kingdom (UK). Yet as with many western developed nations, migrant care workers make a substantial contribution to the older adult health and social care sectors in both countries. Together with global factors, such as population ageing and increased labour participation of women, high vacancy and turnover rates, due to poor working conditions (Eborall and Griffiths 2008; McCarthy, Tyrell and Lehane 2003), have driven demand for migrant care workers in Ireland and the UK. Recent survey findings suggest that 28 per cent of care workers in the UK long-term care

* Irish Centre for Social Gerontology, National University of Ireland Galway, Ireland.

$\dagger$ Department of Social Policy, London School of Economics and Political Science, UK.

\section{CAMBRIDGE}


sector and 32 per cent in the Irish long-term care sector are migrant workers $^{1,2}$ (Cangiano et al. 20o9; Walsh and O'Shea 2009).

It is this reliance on migrant workers in older adult care that raises interesting questions around the dynamics of the care relationship. With seemingly opposing shifts in the older adult care sector, in terms of recessionary-induced expenditure reductions, on one hand (Hillyard et al. 2010), and increased emphasis on quality of care, on the other (Howse 2007; National Economic and Social Forum (NESF) 2005), such questions certainly become more complex. However, the majority of research on formal migrant care workers concentrates on general health-care migration (Buchan 2007; Khadria 2007; Lorenzo et al. 2007; Pittman, Aiken and Buchan 2007). Migrant care workers caring for older people, and particularly the relationship that connects these two groups, has not been well investigated in the international literature (Kiata and Kerse 2004), let alone in the contexts of Ireland and the UK. Given that both migrant workers and older people are potentially vulnerable groups, and that the sector is considered to be inherently disadvantaged (Smith and Mackintosh 2007 ), the current lack of understanding is potentially detrimental to care practice and policy development.

This paper aims to address this knowledge deficit by: exploring the relationship between migrant care workers and older people in Ireland and the UK; the barriers to and the facilitators of these relationships; and the implications for relational aspects of quality of care in institutional and home care settings. The paper draws on data from a multidisciplinary crossnational study on the 'role of migrant care workers in ageing societies' (Cangiano et al. 20og; Walsh and O'Shea 2009).

\section{Quality of care, care relationships and migrant care workers}

Older adult care is recognised as an intimate and sensitive process, intensive in nature, and essential in the support that it provides for older people (Woolhead et al. 2004). Even though, the majority of formal care in Ireland is still provided through long-term care institutions, there has been a move towards community structures both in the UK and in Ireland. In recent years, conceptualisations of care that move beyond medical-orientated models have dominated many policy and guideline documents (Department of Health and Children 2001; NESF 2005). While in Ireland discourse concentrates on a broad, and often ambiguous, 'person-centred' approach, in the UK there has been a more tangible focus on individual choice and service personalisation mechanisms (e.g. direct payments and personal budgets). Even though the success of such measures is still unclear, the 
approaches in both countries emphasise the 'personhood' of the older person and their role, by proxy or otherwise, in deciding the care they require.

Although rarely acknowledged in policy agendas (personalisation-related or otherwise), orientating philosophies of care around the needs and preferences of the older person implicitly centre notions of quality of care on the interpersonal relations between provider and recipient (Brichin 1998; Eales, Keating and Damsma 2001; Eustis and Fisher 1991; Himmelweit 1999; Nolan et al. 2002). Caring comprises not only the physical act of caregiving, but also the relational side of the care giver-care user exchanges, and the connections between these practical and emotional aspects of the process (James 1992; Himmelweit 1999). Nolan et al. (2004) goes further and proposes a shift from individualistic notions of person-centredness to relationship-centredness, reflecting the interdependence between carer and care receiver and the importance of interpersonal interactions in creating a basis for care (also see Nolan 1997).

For older people, the care relationship not only shapes their experiences of care, but as it often represents their core human and social interaction it can also shape their sense of wellbeing, their perceptions of autonomy, and ultimately their quality of life (Bowers, Esmond and Jacobson 2000, 2003; Himmelweit 1999). For care workers, relations with an older person effectively define their everyday working and caring experiences; thereby assisting in the delivery of affective care and reducing care worker stress, or creating additional barriers that must be negotiated (Gottlieb, Kelloway and Fraboni 1994; Lawrence, Tennstedt and Assmann 1998; Lyonette and Yardley 2003; Starrels et al. 1997). With respect to more profound outcomes, Rundqvist and Severinsson (1999) found that relationships with older care recipients could enrich the meaning of work activities for a care worker.

Even in circumstances of cognitive decline care relationships are dynamic co-constructions, built upon environments, interactions and disease progression (Graham and Bassett 2006). Brown-Wilson, Davies and Nolan (2009), in a study of three care homes in England, found that relationships can take a pragmatic form, focusing on instrumental aspects of care; a personal and responsive form, concentrating on the older person; and a reciprocal form, taking needs of residents and staff into account. Other studies have noted that reciprocities, such as gratitude, act as an important mediating factor in the trustfulness, continuity and quality of the relationship (Edebalk, Samuelsson and Ingvad 1995; Quershi and Walker 1989; Lewinter 2003). In essence, successful care relationships can facilitate affective care, incorporating the humane components of kindness and compassion, and moving beyond task-orientated care delivery (Berdes and Eckert 2007; James 1992; Kitson 2003; Lopez 2006). 
There are, however, significant gaps in the literature. At a general level, much of the documented research concentrates on wellbeing outcomes for care-givers (Pinquart and Sörensen 2003, 2006). With the exception of a small number of researchers (Brown-Wilson, Davies and Nolan 2009; Eustis and Fisher 1991; Graham and Bassett 20o6; Lewinter 2003; Piercy 2000), even when studies consider the nature of care relationships they typically do so from the perspective of the care-giver, neglecting the views of the recipient altogether (Brown-Wilson, Davies and Nolan 2009; Lewinter 2003; Piercy 2000). Additionally, research predominantly focuses on informal and family care (Adamson and Donovan 2005; Al-Janabi, Coast and Flynn 2008; Arksey and Glendinning 2007; Lewinter 2003; Spruytte et al. 2002). Consequently, while there is some debate about whether or not moral obligation exists amongst paid carers (Dodson and Zincavage 2007; Eustis and Fisher 1991; Piercy 2000), we know relatively little about the professional care relationship.

In terms of care provision involving migrant care workers, issues concerning transnational dynamics have been noted. Language and other communication barriers can impede the delivery of high-quality care (Brush, Sochalski and Berger 2004; Johnstone and Kanitsaki 2008; Tuohy 2002; $\mathrm{Xu}$ 2008). Likewise, cultural differences in care approaches and norms around ageing have been found to affect the transition of care workers from the care system of one country to another (Berdes and Eckert 2007; Brush, Sochalski and Berger 2004; Johnstone and Kanitsaki 2008; Kiata and Kerse 2004; $\mathrm{Xu} 2007$ ). As these aspects are core to the formation of care relationships, they may fundamentally shape the nature of care interactions.

The attitude of an older care recipient towards the migrant care workforce will also influence the development of the care relationship (Foner 1994). The limited literature on the dynamics of the relationships between older people and migrant care workers has documented both positive and negative attitudes, including incidences of discrimination against migrant care workers and non-acceptance by older people (Berdes and Eckert 2001; Cuban 2008; Doyle and Timonen 2009; Hagey et al. 2001; Scrinzi 2003). Racialised hierarchies have been shown to play a role in the construction of attitudes towards care workers, based on cultural stereotypes and assumptions about the characteristics of workers according to race/ethnicity: Loveband (2004) found that cultural stereotypes were in operation in the recruitment of particular migrant groups for domestic care.

In addition, there are concerns about how to preserve the entitlements of migrant care workers and older people. There is evidence to show that carers' rights are sometimes viewed as secondary to those of the care 
recipient, especially when the care relationship is mediated by an employer (Dodson and Zincavage 2007). There is also evidence of unlawful conditions of employment for migrant care workers, including the withholding of wages by employers (Wilkinson, Craig and Gaus 2010). By contrast, there have been a number of studies and highprofile cases of neglect and abuse that have highlighted the power advantage that carers have over care users (Ayalon 2011; The Commission of Investigation 2009). As Dodson and Zincavage (2007) note, it is a critical concern that the humanity of one group is not sacrificed for the sake of that of another.

Other factors intrinsic to the care environment may impact on the care relationship. At an organisational level, these involve characteristics of employment; organisational philosophies of care; workload schedules and bureaucratic reporting (Fredrikson and Scharlach 1997; Lyonette and Yardley 2003). At the level of care delivery, potential influences include the continuity of care; the length of time that care has been provided; and the dependency level of the older care recipient (Berdes and Eckert 2007; Piercy 2000). These factors may of course also influence the development of care relationships between host country care workers and older people.

It is important too to recognise the wider social and structural context of the sector within which the care relationship takes place. Aside from recessionary cut-backs, there are long-standing concerns in both countries about funding, care worker training, quality of care and regulatory structures (especially home care) in a sector that is seen as embodying low-status gendered social roles of care labour (Commission for Social Care Inspection 2008; McKinlay and Cowan 2003; NESF 2005; Smith and Mackintosh 2007). It is unsurprising then that older adult care is considered a disadvantaged employment sector in Ireland and the UK. A number of international studies have also expressed concern that the care labour market is embedded in divisions of class, race and immigration status divisions that some have argued have served to strengthen a public and political stigmatisation of older adult care (Berdes and Eckert 2007; Dodson and Zincavage 2007; Dyer, McDowell and Batnitzky 2008; Foner 1994; Kiata and Kerse 2004).

Drawing on the international literature on care relationships, the analytic framework for this paper, and for the comparative analysis of Irish and UK data, focuses on three areas: (a) older care recipients' and migrant care workers' perceptions of quality of care and a good carer - in particular, whether relational aspects of care are considered to be central to these areas; (b) care relationship themes - what for older care recipients and migrant care workers are the primary themes within the care relationship and 
what part do elements of reciprocity, need and discrimination play within these relationships; (c) influences on care delivery and relationship development-whether older care recipients, migrant care workers and employers consider such factors as language and communication, and organisational structures to shape the care relationship. The framework did not differ across countries and is used as a basis for the presentation of the findings which is spilt across these three areas.

\section{Approach and methodology}

This paper used a mixed-method approach structured around the key informants of migrant care workers (registered nurses and care assistants) and older adult care users. The inclusion of data from both sources was necessary to capture the full dynamic of the care relationship (BrownWilson, Davies and Nolan 2009), although participants were independent informants and did not belong to care dyads. The primary focus of this paper concerns migrant care workers' and older peoples' perspectives and experiences, however, employer/provider perspectives were also included in the analysis. These data were particularly useful for understanding influences on care delivery and relationship development, and for ascertaining the impact of the care relationship on the quality of care delivery.

The study protocols were developed in collaboration for Ireland and the UK and were reviewed and approved by independent university ethics committees in each country. The data were collected between 2007 and 2009.

\section{Focus groups with older adults}

Six focus groups were held with 41 older people across Ireland and the UK. In Ireland, two focus groups were organised with 15 older participants ( 14 female; one male), all of whom were currently in receipt of care and lived in a nursing home.3 The participants were White, Christian (vast majority Catholic) and apart from one UK citizen were all Irish nationals. In the UK, four focus groups were organised with 26 older participants ( 23 female; three male). This included two focus groups with recipients of care who lived in two separate care homes $(\mathrm{N}=17)$ and two focus groups with home care service users $(\mathrm{N}=9)$. All participants were British nationals; 21 participants were White British and five participants were British Asian. Focus group topics in the Irish and UK sites explored (a) preferences and plans for care; (b) experiences with and attitudes towards migrant care workers

\section{CAMBridge}


and (c) positive and negative aspects of being cared for by a migrant care worker.

\section{Interviews with migrant care workers}

Individual semi-structured face-to-face interviews were carried out with 34 migrant care workers in Ireland and 56 migrant care workers in the UK. The sample included registered nurses, senior care workers and care assistants working in home care and residential care settings.

Migrant care workers were recruited through residential and home care providers, migrant organisations, community and religious organisations, trade unions and with the use of snowball sampling. Nearly all participants ( 84 out of 9o) had arrived in Ireland/the UK in the ten years preceding our fieldwork. With reference to Table 1, the total study sample included 12 male and 78 female participants who came from the key source countries for migrant care workers in Ireland and the UK.

Areas of interest covered by interview questions included (a) migrant care workers' perceptions of what is required to be a good carer (e.g. skills, characteristics, training); (b) their role and responsibilities (e.g. workload, type of care delivery and composition of care recipients); (c) employment conditions (e.g. remuneration, working hours and general job satisfaction); and (d) their relationships with their care recipients (e.g. nature of relationship, positive aspects and challenging aspects).

\section{Employers/providers and data collection}

Employer/provider data were collected through national surveys and semistructured telephone interviews. In Ireland, a postal survey was distributed to all older adult long-stay care institutions (public, voluntary and private), and as many home care organisations as could be identified $4(\mathrm{~N}=570)$. Fifty per cent of surveys were returned $(\mathrm{N}=284)$. In the $\mathrm{UK}$, a postal survey was sent to a random sample of care homes $(\mathrm{N}=3,800)$ and a random sample of UK Homecare Association members $(\mathrm{N}=5$ oo $)$. Overall, 557 questionnaires were returned providing a 12 per cent response rate.5 Sixteen semistructured telephone interviews in Ireland and 30 in the UK provide the primary employer/provider data for this paper. Participants were selected from the survey respondents in the two countries and included employers from the home care and residential sectors. The interviews explored the questionnaire topics in more detail, which included (a) reasons for hiring migrant care workers; (b) experiences with migrant care workers and (c) impact of hiring migrant care workers on quality of care. ${ }^{6}$ The employer/ provider data are used in this paper to present findings on influences on care delivery and relationship development.

\section{CAMbridge}


T A B E 1. Demographic and employment characteristics of migrant care worker sample

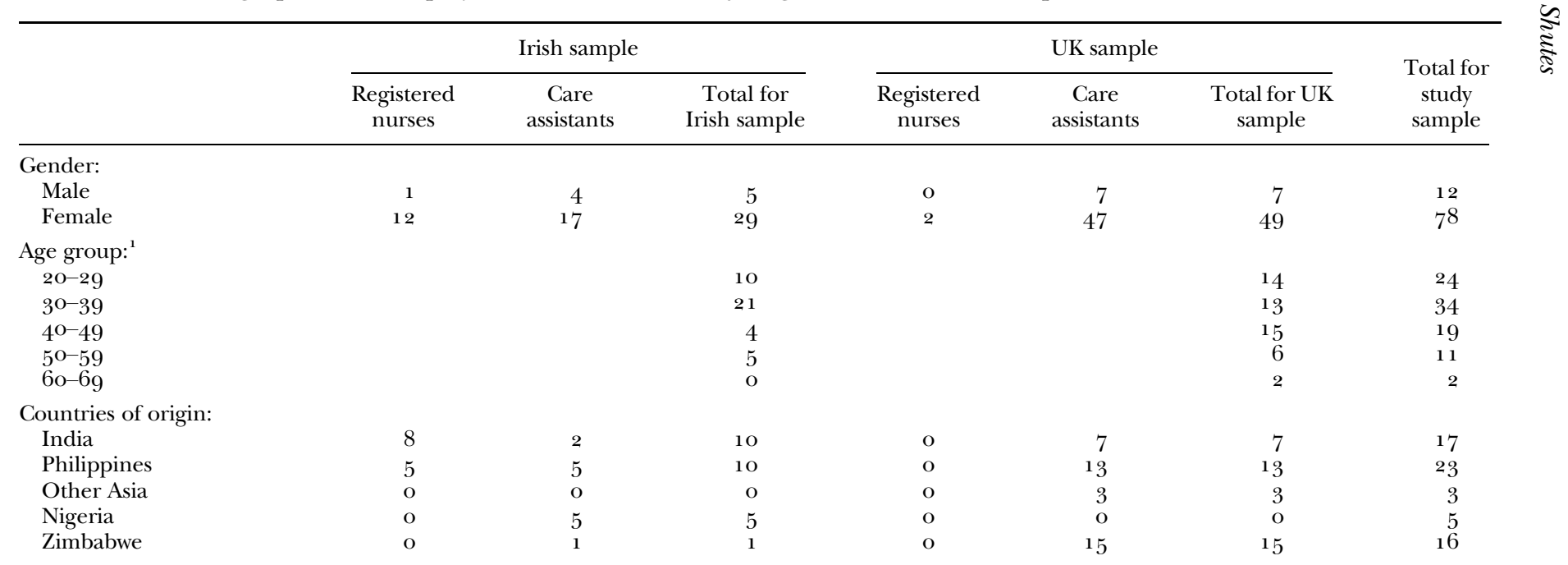

\section{CAMbridge JOURNALS}


Poland

Other Eastern Europe

Work setting: ${ }^{2}$

Public long-stay care

Private care home

Voluntary long-stay care

Public home care

organisation

Private home care

organisation

Direct-employ live-in

Across multiple settings

Care worker qualification:

Formal care

qualification

3
1

6

1

6

(. Six people did not provide their age in the UK sample. 2. In Ireland, long-stay care facilities provide health and social care and consequently al registered facilities (public, private and voluntary facilities) must be supported by nursing and clinical expertise. In the UK, nursing home facilities provide health and social care and are supported by nursing personnel. Residential homes provide social care and do not require nursing personnel. 3. Eleven of these care assistants in the UK held nursing or other professional health qualifications.

Source: Migrant care worker interview questionnaire.

\section{CAMBRIDGE}




\section{Data analysis}

All interviews and focus groups were audio recorded, transcribed and coded. Within each country team, individual researchers first developed a set of inductive codes from a sample of interview transcripts. To develop a coding frame, these codes were then cross-referenced and checked by the research team, on the basis of qualitative analytic criteria (credibility, dependability, and confirmability; Guba and Lincoln 1994) and qualitative coding considerations (including what the code is about; what the code represents; and of what topic and category the code is an instance) developed by Lofland and Lofland (1995). The coding frame was then compared across countries to ensure broad consistency and refined as thematic analysis was performed on each country data-set. Atlas TI (for Irish data) and NVivo 7 (for UK data) qualitative data analysis software was used to assist in this regard. Guided by the analytical framework developed from the literature for this paper, thematic commonalities and differences across the country data-sets were then identified by the authors and used as a basis for the comparative aspects of this paper. The employer survey data were collated, cleaned and analysed through descriptive statistics with the use of SPSS ${ }_{15}$. However, it is only response proportions from the survey that will be reported in this paper.

\section{Perceptions of quality of care and a good care worker}

To understand the expectations of the care relationship, we will first describe the care preferences of the older care recipients and what in the view of the older participants and migrant care workers constitutes quality of care and a good care worker.

Irrespective of where care is being delivered, older care users acknowledged that 'the most important thing is that you are just cared for'. For older participants, the principles that were associated with family care (e.g. love, compassion, kindness and trust) underlined their preferences for care-giver qualities. To some degree this was also true for migrant care workers and how they viewed the caring process. While training was seen by all participants as important for care delivery-particularly those with formal nursing qualifications - it was for the most part seen as secondary to the relational aspects of care. The care relationship, therefore, was considered a core determinant of the quality of care by older people and by migrant care workers.

I know that the skills are very important too, but sure if you haven't compassion for the person that you're with or that you're looking after, what good is it all. Do ya know, if your not kind and that. (Female older care user, Irish nursing home resident; IRLFG 2) 
To have empathy and respect for an 'older person's situation' were also held as valuable attributes for a care worker. Recognising the care user as a person and trying to preserve their dignity and personhood was said to facilitate a stronger bond between the care worker and care user. To be patient with and to listen to the care user was mentioned as a necessity by migrant care workers and older people. Similarly, communication was considered crucial so as to identify the needs of older people; to understand an older person's perspective and to fulfil the socialisation elements of the care process.

\section{Care relationship themes}

While predominantly positive, care relationships emerged as complex multifaceted constructions. In this section, we will use data from interviews with migrant care workers, and focus groups with older care users to explore the key themes that emerged around care relationships. These themes were need orientated, friendship and familial-like, reciprocal, and discriminatory. In some cases the themes represented the primary descriptors of the relationship. In most instances, however, the themes were not mutually exclusive, existing in parallel across the multiple care relationships of one care worker or intertwined within a single care relationship.

\section{Need orientated}

For some, the nature of the relationship was defined by the demands of the care environment. This related, in part, to a care worker's workload, but more so to relationships orientated around care requirements. Migrant care workers spoke about high-dependency care environments and the challenges of caring for older people with a diverse set of physical and emotional needs. Several participants noted the additional difficulty in delivering care to older people who suffered from Alzheimer's disease or the other dementias. The behaviours that these conditions could induce were found to be especially challenging, particularly with respect to developing a care relationship.

Oh it was very stressful for me when I came and I saw what a huge amount of people suffering from such disease... So Down Syndrome, Alzheimer, dementia, strokes, people come after hospital - a lot of people come just for a few weeks, they cannot move, they cannot walk! (Ukrainian female care assistant, Irish private nursing home; IRLI 11 )

For the most part, where a need-orientated theme dominated interactions between migrant care workers and older people, their relationship was 
focused on reducing the stress on the recipient and making the person as comfortable as possible.

\section{Friendship and familial-like}

The majority of migrant workers in this study described relationships with older care recipients that went beyond service provider and service user. Participants spoke about a closeness and a personal attachment to the people they cared for. These feelings were evident in many ways, including an emotional loneliness for the older care users after leaving work.

I miss them, I don't know why. If I am at home, I will be watching the clock, I'll be looking ... because we have a routine ... So if I'm at home, I will just be watching at the clock, and guessing exactly what is going on! [laughter]. (Nigerian female care assistant, Irish public long-stay facility; IRLI 02)

Other migrant care workers described how the care relationship evolved into a friendship with recipients. In a similar manner, a number of older care users highlighted that their migrant care workers represented more to them than just service providers and described how a sense of companionship often characterised their interactions.

We are more friends than anything now. She is lovely, she really is. She is a ray of sunshine. As soon as she comes in the door it's all laughs with her. She's got a terrific sense of humour. (Female older care user, UK home care user; UKFG 3)

Deeper feelings of familial-like attachment, responsibility and love were also evident within the research. Unlike the theme of friendship, which required a more active interpersonal interaction, and therefore was more likely to involve non-cognitively impaired care users, familial-like connections were operational in relationships with care recipients of all dependency levels. There was a distinct appreciation and fondness in the care users' accounts of the relationships that they formed with their migrant care workers. The labels of sons, daughters, parents and grandparents were frequently used by both migrant care workers and older people to illustrate the strength of the relations between care-givers and care users.

We are like granddaughter and granny, the relationship is like that. We always have a good laugh, we always talk about everything. (Filipino female care assistant, UK live-in care worker; UKI 25)

Moreover, the meaning of these forms of relationships (familial-like and friendship) was evident within care workers' descriptions of loss stemming from moving jobs or the death of one of their care recipients.

There have been instances that I've been attached to older people, when they pass away, I just can't accept it like. (Indian female nurse, Irish private nursing home; IRLI 30) 


\section{Reciprocal}

Care relationships were, in many cases, defined by reciprocal elements. While also evident in friendship and familial-like connections, reciprocity was primarily embedded in the characteristics of care work itself and the mutual investment required in the relationship. It is fair to say that to some degree, these elements were common to most participants. Migrant care workers talked about making a difference through their work and highlighted the positive feelings that they obtained from helping other people.

Sometimes you all for them ... and you be carer; you be friend; you be family; you be assistant; you be everything for them. And ... you feel really confident in your job, and you feel important for them or something, I don't really know the feeling, but I feel ... oh I can help them. (Latvian female care assistant, Irish public long-stay facility; IRLI o8)

For some care workers, the appreciation expressed by older people and their families fostered feelings of accomplishment and achievement. This in turn reaffirmed an individual's capacity as a care-giver, enhancing their selfesteem. Personal growth and development were highlighted as significant benefits of caring for older people. The emotionally laden and intimate nature of care work appeared to help care workers to form a clearer awareness of their own context and the perspective of others.

It's helped develop me as a person: it's toned me down, understand myself; understand my environment; understand the other person that I'm dealing with really ... I've learned from it. (Nigerian female care assistant, Irish voluntary long-stay facility; IRLI o7)

For older care users too, there was an appreciation of the reciprocal elements within the caring process. On one level, this referred to the pragmatic exchange of care for financial payment. On another level, this appreciation was linked to an exchange of cultural information that served as a form of cross-cultural learning for both older people and migrant care workers. Ultimately, care users recognised that the success of the relationship was dependent on the attitudes of both the care worker and the older person. Without a mutual investment, it was felt that any caring relationship would be undermined.

[Depends] on your own attitude towards your carers and the people that are in here. If you're friendly and kind to them, it makes a great difference. (Female older care user, Irish nursing home resident; IRLFG 2)

\section{Discrimination}

For some migrant care workers in Ireland and the UK, experiences of race discrimination were evident in their care relationships. This theme was 
particularly strong for care workers from African countries of origin, but also for some care workers from South Asian and South-East Asian countries. A number of migrant care workers recounted occasions where older recipients openly favoured 'white', 'English' or 'Irish' workers, and sometimes refused to be cared for by 'black' or 'foreign' care workers.

I had one time ... one lady ... she was very agitated and she kept on ringing her bell and one time I said 'are you ok?' and she goes 'listen just go away! I don't want a black nurse around me...I don't want... I want my own Irish nurses.' (Zimbabwean female care assistant, Irish public long-stay facility; IRLI 10)

While in some cases, the incidents arose from the first interaction with an older person, in other cases abusive behaviour came from an existing and previously valued relationship.

I don't see myself as black, I just see myself as a human being, as a care assistant. So if the bell rings, if I walk in ... you don't expect to be told 'you are black'. It was kind of a shock, because I was like 'oh no!' I swear to God, I shed a little tear, I went into the bathroom and I cried because I said to myself . . . this lady I loved her, but I didn't expect that something would come out of her mouth of saying 'I don't want you near me, you are black' - I didn't expect that. (Zimbabwean female care assistant, Irish public long-stay facility; IRLI 10)

Migrant care workers highlighted that discrimination was sometimes articulated through grievances about language proficiency or issues around national accents.

She likes white people more than me. Sometimes, when she talks to me, she will know what I'm talking about, but if she sees other white people, she will say she can't hear what I'm talking about, 'I can't hear your accent, what are you saying.' (Zimbabwean female care assistant, UK live-in care worker; UKI $3^{6}$ )

However, in the UK, the discriminatory preferences for particular care workers were likewise shaped by the cultural and ethnic diversity of the older population.

This Chinese lady, she's had different carers. The last one is from her country, she's Chinese. But she's had a Muslim girl and she's had a black girl there. But I think she was not satisfied. (Zimbabwean female care assistant, UK home care organisation; UKI 12 )

The complexity of discrimination was affected by sites of care. The nature of home care delivery, namely individual placements and one-to-one interactions, increased the pressure on the care worker to be accepted and to ignore discriminatory behaviour.

You read it all over them, if they really want you... I did just two days, and it was hell. It was hell. Because I'm black, he doesn't want me... You try your possible best, you clean ... do what you don't have to do: you mop; you make sure the house is extra clean; you do your work. Some of them, if they don't want you, 
they don't want you. (Nigerian female care assistant, Irish live-in care worker; IRLI 23)

Being dependent on an employer for work and accommodation amplified the vulnerability of a live-in care worker. The boundaries between work and leisure were not always clearly defined, with free time and private space often being transgressed.

Some migrant care workers reported that instances of discrimination were sometimes concentrated in the initial period of care delivery. Issues surrounding trust and care worker preference occurred frequently during this period. Others considered the attitudes exhibited by older people to stem from a lack of experience with other nationalities. While a number of migrant care workers considered discriminatory attitudes, particularly racism, to be generational, reflecting the typical beliefs of the current cohort of older people. The role of mental health and particular neurodegenerative conditions, such as Alzheimer's, was also highlighted. Older people suffering from these conditions were in some cases considered more likely to be abusive towards migrant care workers.

Regardless of the different rationales that migrant care workers ascribed to their experiences of discrimination, these experiences exposed the divisions of race and ethnicity that can shape the relationship between older people and migrant care workers.

\section{Influences on care delivery and relationship development}

There were particular factors that shaped the development of a care relationship between a migrant care worker and an older person. These factors influenced the extent to which the various themes, outlined in the previous section, were evident in the relationship between older people and migrant care workers. Data from interviews with migrant care workers, focus groups with older care users and from the employer/provider telephone interviews (quotes) and the employer/provider survey (percentage responses) are used to describe these factors.

\section{Language and communication}

Language and communication was a significant challenge for older people, migrant care workers and employers/providers within the research. In the employer/provider survey, $6_{5}$ per cent of respondents in Ireland and 66 per cent in the UK reported that poor English-language proficiency was a significant challenge in hiring migrant care workers.

I think communication skills are the biggest concern I would have. Because they [migrant care workers] speak too low, the residents are half deaf and they're nervous

\section{CAMBRIDGE}


when they come in and I think the communication really would be the major thing. (Proprietor, Irish private nursing home; IRLTI o1)

For those care workers who lacked English-language proficiency, the delivery of basic care to older people was compromised by the difficulty in understanding the older person's needs and preferences.

It's like we were talking to the residents with the dictionary and the patients were just waiting you know while you check with the book. (Filipino female nurse, Irish private nursing home; IRLI 20)

The social and conversational aspects of care that older people valued so highly were often restricted due to communication difficulties. From the perspective of older care users, these limitations meant that a connection with a care worker was that more difficult to form.

You know, we don't understand [them], and you can't always joke because they don't understand the joke. It's a bit difficult but you do try. (Male older care user, UK nursing home resident; UKFG 04)

In Ireland, older care users and employers/providers highlighted that migrant care workers speaking in their native language when they were alone with care recipients was also an issue and led to feelings of distrust in the care relationship.

The challenges around language and communication were not just in terms of language proficiency. Some migrant care workers described the complexities that regional accents and colloquialisms introduced into conversations, even if they had high levels of English-language proficiency. Similarly, an Irish employer described how a migrant care worker had interpreted a female resident's desire to 'spend a penny', which is a colloquialism for wanting to use the toilet, as a request to go shopping.

The diversity of language needs amongst older people also complicated issues around communication. In the UK, care workers were needed who could speak the language of minority ethnic groups of older people, while in care environments in Ireland some older people only spoke Irish Gaelic.

\section{Culture - history, customs and care approaches}

A number of employers/providers in Ireland felt that not having a shared cultural outlook with the older person could in some instances hinder the development of a strong care relationship.

When you are talking about historical [understanding], [migrant care workers] haven't experienced ... for example ... the 1916 rising ... whereas when I would go down the ward and if I meet an older person I could say to them 'And what part of the country are you from?' They haven't that ... cultural historical background of older

\section{CAMBridge}


Irish people ... you get a cultural awareness, but do you have an understanding of the history? (Proprietor, Irish private nursing home; IRLTI o6)

Lack of understanding around customs and traditional food and beverage preparation were also considered to be constraints.

How to make a cup of tea for example, she [Hungarian migrant care worker] was just making half a cup of milk and just a bit of tea. So everybody was criticizing the tea because it was cold, and I taught her how to make it. (Female older care user, UK care home resident; UKFG O1)

As with communication, the diversity of older adult cultural backgrounds in the UK was highlighted by British Asian participants, with some individuals expressing a preference for care workers who had an understanding of Sikh customs. Similarly, employers/providers in Ireland mentioned that when a care workers was from a common religious background (e.g. Catholicism), forming a connection did not appear to be as much of an issue. For Irish older care users, a sense of a shared migratory experience was also evident and provided some nursing home residents with a perceived link to migrant care workers.

I feel that because we have always been immigrants anyway ... it's nice to think we can sort of [cope] in the reverse now ... you would probably resent people if you didn't have that experience. (Female older care user, Irish nursing home resident; IRLFG 2)

Differences were also referred to in terms of approaches to older adult care. The clinical ability of nurses (particularly those from India) was highly praised by some Irish employers/providers in interview, but their lack of social-care experience was mentioned as a potential barrier. This was particularly an issue for care workers recruited from acute settings in countries with no formal older adult care sector (such as India and the Philippines).

The bottom-line challenge is that the standard of care is maintained and with it the patient-centred approach to care. And for a patient-centred approach to care you have to know where the patient is coming from, you have to know the culture of the patient. Irish workers find that difficult not to mind migrant workers ... (Director of nursing, Irish private nursing home; IRLTI o8)

However, some employers/providers and older people praised migrant care workers, or particular groups of migrant care workers, for their strong caring ethos and care-related qualities (e.g. compassion).

Their culture and their belief and their value system, in a lot of cases would be similar to our own and Ireland in the past maybe. (Director of nursing, Irish public long-stay facility; IRLTI 11 )

This also points to the potential role of cultural stereotypes in employers' and older people's appraisal and acceptance of migrant care workers. Care 
workers were ascribed particular characteristics/skills on the basis of their ethnicity or nationality by some interviewees, with reference made to a 'caring culture' (as applied to workers from the Philippines and to an extent India) and a 'hard-working culture' (as applied to workers from Eastern Europe).

\section{Organisational and structural characteristics}

Care relationships operated in the environmental context within which they were performed and were, therefore, susceptible to the influence of macro- and micro-contextual characteristics of the organisation and the sector.

The descriptions of older adult care portray a busy and, for some care workers, a hectic daily workload. While there were certain distinctions across settings and recipient dependency, the everyday duties of care workers encompassed an extensive range of responsibilities, including aspects of personal, social and health-care provision.

In the morning you come in ... you get all about the patients you have and what's the story with them. Then you start doing washes, you do breakfast, you feed the patients ...Then you make sure they're comfortable, they're sitting out, and then you ... hoist them in and out again, because they can sit out for maybe full hour, and then you get [them] back in the bed... Like a bit busy, heavy day, yeah. (Latvian female care assistant, Irish public long-stay facility; IRLI o8)

Care workers described how working within such a demanding environment meant that the development of a care relationship was sometimes secondary to the work routine that had to be performed. This was particularly evident in accounts of care environments with staff shortages. For older care users, the allotted time for care delivery was an issue, with several participants in the UK sample expressing their dissatisfaction with the time allocated to their care. Migrant care workers described how the schedule-driven environment could undermine the focus on the older person.

If I don't have time, I can't develop a good relationship with them ... Sometimes I forget their names. It's a shame but, you know, I can't remember every name when I'm working in 20 or 30 different homes and I meet hundreds of people. I'm trying to remember their names and to remember them, their needs, what they like, what they don't like. (Polish female care assistant, UK home care organisation; UKI 35)

Conversely, organisations which had adopted a philosophy of care with a strong focus on the care user were more likely to facilitate care provision over a longer period. Aside from insufficient time to establish relational stability, older care users and migrant care workers described how the

\section{CAMbridge}

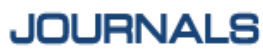


continuity of the care relationship can be threatened by staff turnover rates, care worker rotation and the rationing of publically funded home care services.

These factors in turn impact on the quality of care provision. Employers/ providers and older care users expressed concern for the state and status of older adult care in Ireland and the UK. This, however, was not due to the impact of migrant care workers on the quality of care: in the employer survey, 61 per cent of employers surveyed in the UK and 58 per cent in Ireland said that migrant care workers did not affect the quality of care, whereas 33 per cent of Irish employers and 30 per cent of UK employers said the quality of care had improved. Concern instead focused on issues around statutory prioritisation and resource allocation, and the value that is placed on older adult care. The lack of support for assisting migrant care workers and employers, when care workers first start working in the sector, was specifically highlighted.

\section{Discussion}

The purpose of this paper was to provide insight into the experiences of migrant care workers and older people in developing and maintaining care relationships in an increasingly strained sector, in two different host-country contexts. There were a number of limitations to this research. First, while the focus groups were insightful, individual interviews with older people may have provided a richer set of data for analysis. Second, focusing on specific care dyads may have unearthed a deeper understanding of relationship dynamics - albeit on a smaller scale with a more complex set of ethical issues to negotiate. Third, the care relationship occurs amidst other relationships with employers and recipient family members, which are not explored in this analysis. These are areas for future research. Nevertheless, this paper offers a number of important insights into a set of circumstances that have rarely featured in the international literature.

The relationship between older people and migrant formal care workers is multifaceted in its construction and possesses a layered complexity that draws on individual, structural and temporal factors, including perceptions surrounding quality of care. The need orientated, friendship and familial-like, reciprocal, and discriminatory themes observed in this research illustrate the diversity of relationship dynamics amongst older people and migrant care workers in institutional and home care settings. Interestingly, apart from discriminatory dynamics, these themes were evident for all participants across different nationalities. The findings are

\section{CAMBridge}


also representative of previous studies in the international literature. Elements of reciprocity, familial and friendship connections have been found by other researchers to be at the heart of care relationships (BrownWilson, Davies and Nolan 2009; Edebalk, Samuelsson and Ingvad 1995; Graham and Bassett 2006; Lewinter 2003), although these studies did not focus on migrant care workers. Instances of discrimination have likewise been documented (Dodson and Zincavage 2007; Timonen and Doyle 2009), but importantly have not previously been connected to an analysis of care relationship dynamics.

Less developed in the literature is the way in which these themes can coexist and intersect to characterise the nature of care relationships. On one level this refers to multiple relationships. For migrant care workers, each care relationship that they are involved in may be dominated by, or described by, a different theme. Similarly, older people who have a number of caregivers may have different kinds of relationships with each person, or may have insufficient time with a care worker to develop relational continuity (Haggerty et al. 2003). In these circumstances, it is really only by understanding the dynamics across the multiple combinations of care worker and care user that we can fully appreciate how such relationships influence the care process in a given setting.

Perhaps more difficult to disentangle though, is how the various themes are intertwined within a single care relationship. In some cases this could be as a result of simple differences in perception between older care recipients and migrant care-givers. For instance, McGilton and Boscart (2007) showed that care workers and long-term care residents defined relationship closeness in different ways. Alternatively, it may be a reflection of how a relationship changes with the progression of illness or over time (Graham and Basset 2006). For example, in the findings of this research a Zimbabwean female care worker (in Ireland-IRLI 10) experienced discrimination in a relationship that she previously had cherished. Thematic dominance within a particular relationship may also depend on the type of care being provided at any given time (e.g. personal care versus shorter routine interactions); the mood of the contributing parties; or the interconnections between the various themes (e.g. friendship relationships often possessed a significant element of reciprocity).

Contextual factors both specific to migrant care workers and the sector in general, and perceptions of what constitutes good care, underlie and feed into the development and maintenance of care relationships. In this way they may also influence how various themes within a care relationship co-exist or alternate.

Language and communication (in terms of proficiency and regional accents and colloquialisms) and culture (history, customs and care 
approaches), were factors that influenced the care relationship. This has been documented in the international literature, but primarily in the context of care delivery (Dyer, McDowell and Batnitzky 2008; Johnstone and Kanitsaki 2008; Tuohy 2002; $\mathrm{Xu}$ 2007, 2008), as opposed to the dynamics of the formation of the care relationship. In this study, the ability to communicate, understand cultural norms and deliver care in a culturally appropriate manner was fundamental to the development of relational aspects of care. In most cases, work experience in Irish and UK care settings and formal training helped to overcome some of these issues. However, the research also highlighted the complexity and difficulty in fulfilling language and culture-based needs in a heterogeneous population of older people. While certainly this was more evident in the UK, where the older population is more diverse in terms of ethnicity and countries of birth, this too was an issue in Ireland due to Gaelicspeaking communities and a growing foreign national cohort of older people.

In addition, the findings illustrated that shared cultural aspects, such as common religious backgrounds (also found by Narayansamy and Owens 2001 ) and experiences of migration (particularly in the case of older Irish participants) could help to foster connections, and thus a stronger care relationship. The findings did show that, for some care workers, particularly of African origin, acceptance and discrimination was an issue. A full discussion of the complexity and construction of discriminatory behaviour in these settings is outside the scope of this paper. It is important, however, to acknowledge the diverse set of underlying drivers in operation including racism; cultural stereotypes and stigmatisation; lack of experience/interactions with people from other countries of origin, live-in care settings and neurodegenerative conditions. Comparable findings have been documented in the literature (Allan et al. 2004; Dodson and Zincavage 2007; Timonen and Doyle 2009).

Interestingly, while cultural and institutional differences in care approaches were evident, relational aspects of care were judged to be a core determinant of quality of care. Being caring, kind and patient superseded the technical skill-sets as constituent qualities for being a good care-giver. Older people and migrant care workers believed these qualities provide a strong foundation from which the relationship can evolve. This supports previous work on care-giving that has linked the development of relational connections with the delivery of affective high-quality care (Berdes and Eckert 2007; James 1992; Kitson 2003; Lopez 2006; Newman, Glendinning and Hughes 2008). At a fundamental level older people, and some care workers, used traditional family associations (such as love and trust) as the benchmark for care delivery. This conceptual basis underlines 
people's expectations and prioritisation when entering and contributing to a care relationship. What is intriguing is that there was a congruency between the opinions of older people and migrant care workers with respect to what comprises quality of care. This might help to explain why the care ethos of migrant care workers was often praised by older people and employers/ providers.

At a more general level, care recipient dependency, significant carer workloads and staff shortages meant that care relationships were even more difficult to develop. This was further compounded by staff turnover rates and care worker rotation. Aside from recipient dependency, these issues undermined the continuity of care for older people and the relational continuity for both older people and the care worker. Similar findings have been documented in previous studies (Lyonette and Yardley 2003; Piercy 200o). Although a care-organisation's ethos may in part have influenced the prevalence of such issues, they are likely to have stemmed primarily from low levels of funding - either as a result of organisational decisions motivated by efficiency or reductions in statutory funding and public-sponsored care contracts. Some have suggested that older adult care itself is an increasingly economically and politically marginalised sector (Cangiano and Shutes 2010; Walsh and O'Shea 2010). Considering the austerity measures that have already been introduced in Ireland and the UK, and the continued economic issues in both jurisdictions, it is difficult to foresee a change in these circumstances.

Most importantly, our research demonstrates the interdependencies that exist within relational aspects of care for professional care relationships. Older people and migrant care workers, in Ireland and the UK, were mutually invested in the care relationship at a physical and emotional level. For migrant care workers, this was in respect to the physical act of care-giving and the emotional strain and rewards that care workers are subject to during care-giving. Whereas for older people, it was in terms of the physical and emotional support that they need and receive through the care process. The nature of care means that the care relationship moves beyond the traditional conceptions and models of service provision. What is more is that our findings indicate that there is a significant element of reciprocity embedded within the care relationship, whether these relationships are characterised by a reciprocal, need orientated, or friendship and familial-like set of dynamics. Older people and migrant care workers are essentially connected in their care experiences and in the products of their experiences - reflecting a relational co-construction (Graham and Basset 2006). The care relationship is, thus, potentially a means of enhancing the wellbeing of both the older person and their carer.

\section{CAMbridge}




\section{Concluding remarks}

The findings of this research demonstrate a need for understanding the care relationship in its holistic form and to recognise the role of both the caregiver and the care recipient in creating and maintaining that relationship. In this manner, while both older care recipients and migrant care workers are potentially vulnerable to marginalisation and prejudice, they should not be viewed as competing for equity in the care relationship. As described by the senses framework (Nolan 1997), those involved in receiving and providing care are entitled to relationships that promote a sense of security, belonging, continuity, purpose, achievement and significance. Certainly, embedding these aspects within the care environment would be valuable for migrant care workers and older people. In practical terms, and to address some of the contextual factors influencing relationship formation, support is required for both parties particularly during the initial transition phase of the care process. An integrated effort, at the national and organisational level, is required around education and training, cultural and care orientation, and procedures and support for reporting and addressing discrimination. The findings also point to questions around prioritisation of older adult care and its impact on quality of care. While the Irish and UK sectors may operate in difficult economic environments, problems with respect to older adult care are long-established in both jurisdictions with recent fiscal patterns just serving to intensify such problems. The consequence is that the care relationship, regardless of the nationalities of care providers, is increasingly situated in a marginalised sector. This paper shows that older people and migrant care workers have worked to develop the care relationship amidst this environment. However, it is perhaps how we view older adult care at the governmental and public level that has to be reassessed, if care relationships are to be supported into the future.

\section{Acknowledgements}

This research was carried out as part of the international project 'The Role of Migrant Care Workers in Ageing Societies', funded by The Atlantic Philanthropies and Nuffield Foundation. The authors would also like to thank all international project partners, including colleagues at the Centre on Migration Policy and Society (University of Oxford), the Irish Centre for Social Gerontology (National University of Ireland Galway), the Oxford Institute of Ageing, the Institute for the Study of International Migration (Georgetown University) and the Community Health Research Unit (University of Ottawa) for their support and collegial contribution to this research. Finally, the authors would like to thank all those who contributed to the research, especially the older people, migrant care workers and employers who participated in this study.

\section{CAMBridge}




\section{NOTES}

1 Although concentrated in the private care organisations in Ireland and the $\mathrm{UK}$, the migrant carer workforce is represented in private, public and voluntary sectors, and institutional and home care settings.

2 Migrant workers are identified in survey data for Ireland as foreign nationals and in survey data for the UK as foreign-born.

3 Irish nursing home residents resided in a private 47 -bed facility staffed by 31 care workers, $4^{8}$ per cent of whom were foreign nationals.

4 Home care is not regulated in Ireland and the exact number of providers is unknown.

5 Local authority providers were under-represented in the sample (6 per cent of residential care homes and 12 per cent of home care agencies registered with the Care Quality Commission (CQC) in England are local authority providers). Homecare providers were also under-represented (the sample comprised one home care agency for every six providers of residential care for older people, while the same ratio among all providers registered with the CQC is one in three). While the sample is skewed to the private sector and to providers of residential care, national data sets indicate that higher proportions of migrant care workers are found in the private sector and in residential care in the UK (Cangiano et al. 2009).

6 For further details on the Irish and UK surveys see the Irish and UK national reports - Cangiano et al. (2009) and Walsh and O'Shea (2009).

\section{References}

Adamson, J. and Donovan, J. 2005. 'Normal disruption': South Asian and African/ Caribbean relatives caring for an older family member in the UK. Social Science $\mathcal{E}$ Medicine, 6o, $1,37-8$.

Al-Janabi, H., Coast, J. and Flynn, T. N. 2008. What do people value when they provide unpaid care for an older person? A meta-ethnography with interview follow-up. Social Science $\mathcal{E}$ Medicine, 67, 1, $1111-21$.

Allan, H. T., Larsen, J. A., Bryan, K. and Smith, P. A. 2004. The social reproduction of institutional racism: internationally recruited nurses' experiences of the British health services. Diversity in Health and Social Care, 1, 2, 11 7-25.

Arksey, H. and Glendinning, C. 2007. Choice in the context of informal care-giving. Health E Social Care in the Community, 15, 2, $165^{-75}$.

Ayalon, L. 2011. Abuse is in the eyes of the beholder: using multiple perspectives to evaluate elder mistreatment under round-the-clock foreign home carers in Israel. Ageing Eं Society, 31, 3, 299-520.

Berdes, C. and Eckert, J. M. 2001. Race relations and caregiving relationships: a qualitative examination of perspectives from residents and nurse's aides in three nursing homes. Research on Aging, 23, 1, 109-26.

Berdes, C. and Eckert, J. M. 2007. The language of caring: nurse's aides' use of family metaphors conveys affective care. The Gerontologist, 47, 3, 340-9.

Bowers, B. J., Esmond, S. and Jacobson, N. 2000. The relationship between staffing and quality in long-term care facilities: exploring the views of nurse aides. Journal of Nursing Care Quality, 14, 4, 55-64.

Bowers, B. J., Esmond, S. and Jacobson, N. 2003. Turnover reinterpreted: CNAs talk about why they leave. Journal of Gerontological Nursing, 29, 3, 36-43. 
Brichin, A. 1998. What makes for good care? In Brechin, A., Walmsley, J., Katz, J. and Pearce, S. (eds), Care Matters: Concepts, Practice and Research in Health and Social Care. Sage, London, $170-87$.

Brown-Wilson, C., Davies, S. and Nolan, M. 20og. Developing personal relationships in care homes: realising the contributions of staff, residents and family members. Ageing E् Society, 29, 7, 1041-63.

Brush, B. L., Sochalski, J. and Berger, A. M. 2004. Imported care: recruiting foreign nurses to U.S. health care facilities. Health Affairs, 23, 3, 78-87.

Buchan, J. 2007. International recruitment of nurses: policy and practice in the United Kingdom. Health Research and Educational Trust, 42, 3, 132 1-35.

Cangiano, A. and Shutes, I. 2010. Ageing, demand for care and the role of migrant care workers in the UK. Journal of Population Ageing, 3, 1/2, 39-57.

Cangiano, A., Shutes, I., Spencer, S. and Leeson, G. 2009. Migrant Care Workers in Ageing Societies: Research Findings in the United Kingdom. Centre on Migration, Policy and Society, University of Oxford, Oxford.

Commission for Social Care Inspection 2008. The State of Social Care in England 2006o7. Commission for Social Care Inspection, London.

Cuban, S. 2008. Home/work: the roles of education, literacy, and learning in the networks and mobility of professional women migrant carers in Cumbria. Ethnography and Education, 3, 1, 81-96.

Department of Health and Children 2001. Quality and Fairness: A Health System for You. Government of Ireland, Dublin.

Dodson, L. and Zincavage, R. 2007. 'It's like a family': caring labor, exploitation, and race in nursing homes. Gender $\mathcal{E}^{\circ}$ Society, $\mathbf{2 1}, 6$, 905-28.

Doyle, M. and Timonen, V. 2009. The different faces of care work: understanding the experiences of the multi-cultural care workforce. Ageing $\mathcal{E}^{\circ}$ Society, 29, 3, 337-50.

Dyer, S., McDowell, L. and Batnitzky, A. 2008. Emotional labour/body work: the caring labours of migrants in the UK's National Health Service. Geoforum, 39, 6, $2030-8$.

Eales, J., Keating, N. and Damsma, A. 2001. Seniors' experiences of client-centred residential care. Ageing $\mathcal{E}^{2}$ Society, $\mathbf{2 1}, 3,279-96$.

Eborall, C. and Griffiths, D. 2008. The State of the Adult Social Care Workforce in England 2008. Third Report of the Skills Research and Intelligence Unit, Skills for Care, Leeds, UK.

Edebalk, P. G., Samuelsson, G. and Ingvad, B. 1995. How elderly people rank order the quality characteristics of home services. Ageing $\mathcal{E}$ Society, 15, 1, 83-102.

Eustis, N. N. and Fisher, L. R. 1991. Relationships between home care clients and their workers: implications for quality of care. The Gerontologist, 31, 4, $447^{-} 5^{6 .}$

Foner, N. 1994. Caregiving Dilemma: Work in an American Nursing Home. University of California Press, Berkeley.

Fredrikson, K. I. and Scharlach, A. E. 1997. Caregiving and employment: the impact of workplace characteristics on role strain. Journal of Gerontological Social Work, 28, 4 , $3^{-22 .}$

Gottlieb, B. H., Kelloway, E. K. and Fraboni, M. 1994. Aspects of eldercare that place employees at risk. The Gerontologist, 34, 6, 81 $5^{-21 .}$

Graham, J. E. and Bassett, R. 2006. Reciprocal relations: the recognition and co-construction of caring with Alzheimer's disease. Journal of Aging Studies, 2o, 4, $335^{-49}$.

Guba, E. G. and Lincoln, Y. S. 1994. Competing paradigms in qualitative research. In Denzin, N. K. and Lincoln, Y.S. (eds), Handbook of Qualitative Research. Sage, Thousand Oaks, California, $105^{-11} 7$.

\section{CAMBRIDGE}


Hagey, R., Choudhry, U., Guruge, S., Turrittin, J., Collins, E. and Lee, R. 2001. Immigrant nurses' experience of racism. Journal of Nursing Scholarship, 33, 4, 389-94.

Haggerty, J. L., Reid, R.J., Freeman, G. K., Starfield, B. H., Adair, C. E. and McKendry R. 2003. Continuity of care: a multidisciplinary review. British Medical Journal, 327, 7425, $1219^{-2} 1$.

Hillyard, P., Lundström, F., Patsios, D., Machniewski, S., Taylor, D. and Lyons, M. 2010. Inequalities in Old Age: An Exploratory Study of the Impact of the Recession on Older People in Northern Ireland (NI) and the Republic of Ireland (RoI). CARDI Grants Programme. Available online at: http://www.cardi.ie/userfiles/Hillyard\% 20 Final \% 20Report\% 20without\%20Appendices\%2020_10_10(2).pdf.

Himmelweit, S. 1999. Caring labor. Annals of American Academy of Political and Social Science, $\mathbf{5}^{\mathbf{6 1}}, \mathbf{1}, \mathbf{2 7 - 3 8 .}$

Howse, K. 2007. Health and Social Care for Older People in the UK: A Snapshot View. Working Paper 6o7, Oxford Institute of Ageing, Oxford. Available online at http:// www.ageing.ox.ac.uk/files/workingpaper_6o7.pdf.

James, N. 1992. Care $=$ organisation + physical labour + emotional labour. Sociology of Health Ẽ Illness, 14, 4, 488-509.

Johnstone, M. and Kanitsaki, O. 20o8. Engaging patients as safety partners: some considerations for ensuring a culturally and linguistically appropriate approach. Health Policy, 9o, 1, 1-7.

Khadria, B. 2007. International nurse recruitment in India. Health Research and Educational Trust, 42, 3, 1429-36.

Kiata, L. and Kerse, N. 2004. Intercultural residential care in New Zealand. Qualitative Health Research, 14, 3, 313-27.

Kitson, A. 2003. A comparative analysis of lay-caring and professional (nursing) careing relationships. International Journal of Nursing Studies, 4o, 5, $5^{\circ} 3^{-10 .}$

Lawrence, R. H., Tennstedt, S. L. and Assmann, S. F. 1998. Quality of the caregivercare recipient relationship: does it offset negative consequences of caregiving for family caregivers? Psychology and Aging, 13, 1, $150-8$.

Lewinter, M. 2003. Reciprocities in caregiving relationships in Danish elder care. Journal of Ageing Studies, 1 7, 3, 357-77.

Lofland, J. and Lofland, L. 1995. Analyzing Social Settings: A Guide to Qualitative Observation and Analysis. Third edition, Wadsworth, Belmont, California.

Lopez, S. H. 2006. Emotional labor and organized emotional care: conceptualizing nursing home care work. Work and Occupations, 33, 2, 133-6o.

Lorenzo, F., Galvez-Tan, J., Icamina, K. and Javier, L. 2007. Nurse migration from a source country perspective: Philippine country case study. Health Research and Educational Trust, 42, 3, 1406-18.

Loveband, A. 2004. Positioning the product: Indonesian migrant women workers in Taiwan. Journal of Contemporary Asia, 34, 3, 336-48.

Lyonette, C. and Yardley, L. 2003. The influence on carer wellbeing of motivations to care for older people and the relationship with the care recipient. Ageing E Society, 23, $4,487-5$ o6.

McCarthy, G., Tyrell, M.P. and Lehane, E. 2003. Turnover rate in nursing and midwifery: the Irish experience. Nursing Time Research, 8, 4, 249-63.

McGilton, K. S. and Boscart, V. M. 2007. Close care provider-resident relationships in long-term care environments. Journal of Clinical Nursing, 16, 11 , $2149-57$.

McKinlay, A. and Cowan, S. 2003. Student nurses' attitudes towards working with older patients. Journal of Advanced Nursing, 43, 3, 298-309. 
Narayanasamy, A. and Owens, J. 2001. A critical incident study of nurses' responses to the spiritual needs of their patients. Journal of Advanced Nursing, 33, $4,44^{6}-55^{\text {. }}$

National Economic and Social Development Forum (NESF) 2005. Care for Older People. Report 32, Dublin: National Economic and Social Development Office.

Newman, J., Glendinning, C. and Hughes, M. 2008. Beyond modernisation? Social care and the transformation of welfare governance. Journal of Social Policy, $37,4,531-57$.

Nolan, M. R. 1997. Health and social care: what the future holds for nursing. Keynote address at Third Royal College of Nursing Older Person European Conference and Exhibition, Harrogate, UK.

Nolan, M., Davies, S., Brown, J., Keady, J. and Nolan, J. 2004. Beyond 'person-centred' care: a new vision for gerontological nursing. Journal of Clinical Nursing, 13, 3a, $45^{-53}$.

Nolan, M., Ryan, T., Enderby, P. and Reid, D. 2002. Towards a more inclusive vision of dementia care practice and research. Dementia, 1, 2, 193-211.

Piercy, K. W. 2000. When it is more than a job: close relationships between home health aides and older clients. Journal of Ageing and Health, 12, 3, 362-87.

Pinquart, M. and Sörensen, S. 2003. Associations of stressors and uplifts of caregiving with caregiver burden and depressive mood: a meta-analysis. Journals of Gerontology, 58B, 2, $112-8$.

Pinquart, M. and Sörensen, S. 2006. Correlates of physical health of informal caregivers: a meta-analysis. Journals of Gerontology, 62 B, 6, $126-37$.

Pittman, P., Aiken, L. H. and Buchan, J. 2007. International migration of nurses: introduction. Health Research and Educational Trust, 42, 3, $1275^{-80 .}$

Qureshi, H. and Walker, A. 1989. The Caring Relationship: Elderly People and Their Families. Macmillan Press, Basingstoke, UK.

Rundqvist, E. M. and Severinsson, E. I. 1999. Caring relationships with patients suffering from dementia-an interview study. Journal of Advanced Nursing, 29, 4, $800-7$.

Scrinzi, F. 2003. The globalisation of domestic work: women migrants and neodomesticity. In Freedman, J. (ed.), Gender and Insecurity: Migrant Women in Europe. Ashgate, Aldershot, UK, 77-9o.

Smith, P. and Mackintosh, M. 2007. Profession, market and class: nurse migration and the remaking of division and disadvantage. Journal of Clinical Nursing, 16, 12, $2213^{-20 .}$

Spruytte, N., Van Audenhove, C., Lammertyn, F. and Storms, G. 2002. The quality of the caregiving relationship in informal care for older adults with dementia and chronic psychiatric patients. Psychology and Psychotherapy: Theory, Research and Practice, 75, 3, 295-311.

Starrels, M. E., Ingersoll-Dayton, B., Dowler, D. W., Neal, M. B. 1997. The stress of caring for a parent: effects of the elder's impairment on an employed, adult child. Journal of Marriage and the Family, 59, 4, 860-72.

The Commission of Investigation 2009. The Leas Cross Commission: Final Report June 2009. Department of Health and Children, Dublin. Available online at http://www.dohc.ie/publications/leas_cross_commission.html [Accessed July 2009].

Timonen, V. and Doyle, M. 20o9. Caring and collaborating across cultures? Migrant care workers' relationships with care recipients, colleagues and employers. European Journal of Women's Studies, 17, 1, 1-17.

Tuohy, D. 2002. Student nurse-older person communication. Nurse Education Today, 23, $1,19-26$. 
Walsh, K. and O'Shea, E. 20o9. The Role of Migrant Care Workers in Ageing Societies: Context and Experiences in Ireland. National Report. Available online at http://www. icsg.ie/Library/documents/ICSG\% 2oMCW\% 2oReport.pdf.

Walsh, K. and O'Shea, E. 2010. Marginalised care: migrant workers caring for older people in Ireland. Journal of Population Ageing, 3, 1/2, 1 7-37.

Wilkinson, M., Craig, G. and Gaus, A. 2010. Forced Labour in the UK and the Gangmasters Licensing Authority. Contemporary Slavery Research Centre, Wilberforce Institute, University of Hull, Hull, UK.

Woolhead, G., Calnan, M., Dieppe, P. and Tadd, W. 2004. Dignity in older age: what do older people in the United Kingdom think? Age and Ageing, 33, 2, $165^{-70 .}$

$\mathrm{Xu}, \mathrm{Y} .2007$. Strangers in strange lands: a metasynthesis of lived experiences of immigrant Asian nurses working in western countries. Advances in Nursing Sciences, 3o, $3,246-65$.

$\mathrm{Xu}, \mathrm{Y}$. 2008. Communicative competence of international nurses and patient safety and quality of care. Home Health Care Management $\mathcal{E}$ Practice, 2o, 5, 430-2.

Address for correspondence:

Kieran Walsh, Irish Centre for Social Gerontology,

National University of Ireland, Galway, Ireland.

E-mail: kieran.walsh@nuigalway.ie

\section{CAMBridge JDURNALS}

